\title{
Role of three-dimensional ultrasound in females with obstructed defecation (in comparison with defecography)
}

\author{
Mahmoud Abdel Latif ${ }^{1 *}$ D, Magda Shady ${ }^{1}$, Nahla M. Elawadly ${ }^{1}$ and Waleed M. Thabet ${ }^{2}$
}

\begin{abstract}
Background: Growing attention of pelvic floor disorders has led to development of new imaging techniques, with increasing importance of ultrasonography. The 3DUS technique is considered an accessible tool for imaging of the posterior pelvic compartment. The purpose of this study is to highlight the role of 3D ultrasound in evaluation of obstructed defecation in females and comparing the findings with defecography.

Results: Study included 30 females classified into two groups: (1) 20 patients (case group complaining of obstructed defecation); (2) ten females (control group-normal nulliparous females). All of them were subjected to defecography and 3D ultrasound during resting, squeezing, and straining. Detection rate of rectocele and intussusception with 3D ultrasound was lower than defecography. By US, significant statistical difference between patients and controls in all measurements of levator hiatus, IS, ES, and PRS thickness during straining ( $P$ value $<$ 0.001). During straining, cut-off value of $20.75 \mathrm{~cm}^{2}$ for hiatal area gives sensitivity of $100 \%$ and specificity of $95 \%$ and using ARA, cut-off value of $105^{\circ}$ gives sensitivity of $98 \%$ and specificity of $90 \%$ for differentiation between patients and controls.
\end{abstract}

Conclusion: Ultrasound can be considered a complementary test to defecography in investigation of patients with obstructed defecation. Ultrasound can diagnose levator muscle attenuation and avulsion, thickness of IS, ES, PRS, and distensibility of hiatal area.

Keywords: 3D ultrasound, Obstructed defecation, Defecography, Internal sphincter, External sphincter, Puborectalis muscle

\section{Background}

Growing attention of pelvic floor disorders over the last two decades has led to development of new imaging techniques, with increasing importance of ultrasonography. Trans rectal, transvaginal, and transperineal approaches, using both two-dimensional and threedimensional (3D) imaging, have made an important effect on the evaluation of the functional anatomy of the pelvic floor. Trans rectal ultrasonography is a wellestablished technique and is considered the reference standard for anal sphincter examination. Transvaginal and transperineal ultrasonographic approaches have been grown in recent years [1].

\footnotetext{
* Correspondence: drlatif72@yahoo.com

${ }^{1}$ Radio Diagnosis, Mansoura University Hospital, Mansoura, Egypt

Full list of author information is available at the end of the article
}

For classification of pelvic organ prolapse, a subdivision into three pelvic compartments is used; the anterior, middle, and posterior compartments. Different symptoms are commonly contributed to prolapse of those three pelvic compartments. Voiding dysfunction and urinary incontinence are commonly related to prolapse of the anterior compartment [2]. Pelvic discomfort, such as feelings of a lump, heaviness, and pelvic pressure, is attributed to all pelvic compartments. Symptoms related to defecatory dysfunction, including obstructed defecation and fecal incontinence, have been correlated with the posterior compartment. It is important to be able to differentiate between different anatomic abnormalities, especially with regards to the surgical intervention needed for treatment of the patient [3].

Ultrasonography has been widely used to evaluate the anterior compartment, including the anatomic interaction 
of the urethra and bladder as part of the mechanism of continence to evaluate implant placement for treatment of stress incontinence in urogynecology [4].

Sonographic imaging of the pelvic floor in women gives superior image resolution compared to the traditional trans-abdominal scanning and defecograpy approach when scanning the pelvis. Structures such as the anorectum, bladder, and the rectovaginal septa are seen with excellent detail, which permits more precise interpretation of normal and pathologic states. It is also minimally invasive, well tolerated, inexpensive, with no exposure to radiation, and shows all the anatomic structures involved with defecation clearly [5].

The three-dimensional ultrasound (3DUS) technique is considered an accessible tool for imaging of the posterior pelvic compartment. It can bring sonographic examination closer to computed tomography or magnetic resonance imaging through its lesser operator dependence, availability of post processing tools, and potential for better standardization of evaluation and measurement planes. This should lead to better understanding of the abnormalities underlying sphincter incompetence and improved predictive value of the diagnosis of sphincter damage [6].

Evacuation proctography (defecography) has been appealed to be the gold standard investigation for objective diagnosis of posterior compartment prolapse. However, defecography is relatively invasive, uncomfortable for the patient, and involves exposure to ionizing radiation [3].

\section{Aim of the work}

The aim of this study was to highlight the role of threedimensional ultrasound in evaluation of obstructed defecation in females and comparing the findings with defecography.

\section{Methods}

This prospective study was conducted from April 2016 to July 2017. It included 30 females classified into two groups: (1) 20 patients as a case group (complaining of evacuation dysfunction and symptoms of obstructed defecation as chronic constipation, pelvic pain, or rectal prolapse), aged from 21 to 50 years. Patients with recent pelvic surgery and pregnant ladies were excluded. (2) Ten females as a control group (normal nulliparous females with normal bowel habits); their ages ranged from 20 to 28 years. All of them were referred to perform defecography and 3D ultrasound examination at radiology center.

A written consent was obtained from all enrolled females. All of the enrollments were subjected to:

(a) Three dimension ultrasound
Ultrasound imaging was performed by using Voluson E8 GE apparatus. Patients were asked to lie in in dorsal lithotomy position, with the hips flexed and slightly abducted. Bladder filling should be partial with empty rectum, and prior voiding is preferable since a full bladder will impede organ descent and increase the likelihood of leakage, making the patient reluctant to perform a proper Valsalva maneuver.

No bowel preparation was needed prior to US imaging. Curved array endovaginal transducer with frequencies between ( 3.5 and $8 \mathrm{MHz}$ ) was placed in the introitus and oriented in the mid-sagittal plane. Imaging was performed at rest and then during a sustained pelvic floor contraction (squeeze) and then during straining. All images were stored on compact disks and analyzed off-line using the proprietary soft wares. Render post processing techniques were done for different phases.

\section{(b) Defecography}

Defecography was performed by using Shimadzu FLEXA Vision. No prior bowel preparation was needed. No opacification of the small bowel was done. After sufficient contrast filling of the rectum $(300 \mathrm{~mL}$ barium paste), the patient was asked to sit on a special commode, contract the pelvic floor musculature, and empty the rectum as completely as possible, then series of images are taken and guided by fluoroscopy in resting, squeezing and straining phases.

\section{Image interpretation}

Ultrasonographic images were analyzed for the following: presence of rectocele and its depth (without gel), presence of intussusception (in 2D images), presence of levator avulsion, measurement of anorectal angle (ARA), measurement of hiatal dimensions and area, measurement of internal and external anal sphincter thickness, and measurement of puborectalis muscle thickness.

Defecography images were analyzed for the following: presence of rectocele and its depth, presence of intussusception, laxity of pelvic floor, and measurement of ARA.

All the ultrasound examinations were performed in succession by two independent radiologists (M. S. and M. L.) and defecography was done in attendance of both. The first radiologist had more than 30 years and the second had about 20 years' experiences in ultrasonic scanning. The results were recorded by consensus of both.

All patients were subjected to surgery. Analysis of data was done and results were recorded. Suggested diagnosis from ultrasound imaging and results were compared with that of defecography as a gold standard to assess value of 3D Ultrasound in the diagnostic approach of obstructed defecation in females. 


\section{Statistical analysis}

The results of defecography and ultrasonography were transferred to SPSS program for statistical analysis. Qualitative data were represented in the form of number and frequency, while quantitative data were represented in the form of mean \pm standard deviation (mean $\pm \mathrm{SD}$ ).

ROC curve and cut-off points were obtained for differentiation of patients with defecation disorders and females with normal bowel habits. All tests were considered significant if $P$ value equals or less than 0.05 .

\section{Results}

This study included 30 female patients classified into 20 female patients with chronic constipation (case group) and ten normal nulliparous females as a control group. Their ages ranged from 20 to 50 years old (mean age 30 years).

The radiological examination (3D sonography and defecography) revealed one or more of these findings: rectocele, intussusception, laxity, and levator avulsion.

3D ultrasound was done and show 17 patients with rectocele (85\%), six patients with intussusception (30\%), and three patients with levator avulsion (15\%). By defecography, 20 patients had rectocele (100\%), ten patients had intussusception (50\%), and 15 patients had lax pelvic floor (75\%); no cases with spastic pelvic floor were encountered (Table 1).

Concerning the size of rectocele, it has been classified into three grades according to Dietz and Steensma [7]: grade I $(<2 \mathrm{~cm})$ in depth, grade II (from 2 to $4 \mathrm{~cm}$ ), and grade III $(>4 \mathrm{~cm})$, but the size of rectoceles defers in defecography and in 3D ultrasonography, as shown in Table 2.

Concerning intussusception, it has been classified into two grades according to Dietz and Steensma [7]: grade I (rectal intussusception): most distal part remains completely intrarectal, and grade II (anorectal intussusception): where the most distal part descending into anal canal. Table 3 displayed that the detection rate of

Table 1 Findings of 3D introital ultrasound in comparison with defecography in diagnosing posterior compartment disorders

\begin{tabular}{lll}
\hline & 3D ultrasonography & Defecography \\
\hline $\begin{array}{lll}\text { Rectocele } \\
\text { Number }\end{array}$ & 17 patients & 20 patients \\
Percentage & $85 \%$ & $100 \%$ \\
$\begin{array}{l}\text { Intussusception } \\
\text { Number }\end{array}$ & 6 patients & 10 patients \\
Percentage & $30 \%$ & $50 \%$ \\
Levator avulsion & & \\
Number & 3 patients & - \\
Percentage & $15 \%$ & - \\
Total number of patients & 20 & 20 \\
\hline
\end{tabular}

Table 2 Grades of rectocele seen by 3D ultrasonography and defecography

\begin{tabular}{llll}
\hline Grades of rectocele & $\begin{array}{l}\text { 3D US } \\
\text { No of patients }\end{array}$ & $\begin{array}{l}\text { Defecography } \\
\text { No of patients }\end{array}$ & $\begin{array}{l}\text { Post-operative } \\
\text { No of patients }\end{array}$ \\
\hline Grade I $(<2 \mathrm{~cm})$ & 4 & 5 & 5 \\
Grade II $(2-4 \mathrm{~cm})$ & 8 & 7 & 7 \\
Grade III $(>4 \mathrm{~cm})$ & 5 & 8 & 8 \\
Total no of patients & 17 & 20 & 20 \\
\hline
\end{tabular}

intussusception with 3D ultrasound was lower than defecography; four patients detected with defecography were missed by ultrasound. By 3D ultrasound, only six cases were diagnosed as intussusception, five cases of them were rectal and only one case was anorectal. By defecography, eight cases had rectal intussusception and two cases have been encountered as anorectal intussusception.

Using 3D ultrasound, levator hiatus, thickness of anal sphincter muscles (internal sphincter "IS" and external sphincter "ES"), and puborectalis sling (PRS) were measured (during rest, squeezing, and maximum Valsalva) to compare between patients (with rectal prolapse) and control group to know the effect of rectal prolapse on distensibility of hiatal area and anal sphincter muscles (Figs. 1, 2, 3, 4, and 5).

Tables 4, 5, and 6 showed that using (independent $t$ test), there was a significant statistical difference between patients and control group in all measurements of levator hiatus and sphincters thickness during straining (maximum Valsalva), as the mean AP diameter, mean transverse diameter of levator hiatus, and mean levator area in patient group were $\left(6.6 \mathrm{~cm}, 4.9 \mathrm{~cm}\right.$, and $\left.23.1 \mathrm{~cm}^{2}\right)$ and in control group were $\left(4.6 \mathrm{~cm}, 3.9 \mathrm{~cm}\right.$, and $\left.15.2 \mathrm{~cm}^{2}\right)$ respectively with $P$ value $<0.001$. The IS thickness in patient and control group was $(1.8 \mathrm{~mm}$ and $2.8 \mathrm{~mm})$ respectively with $P$ value $<0.001$. The ES thickness in patient and control group was $(1.6 \mathrm{~mm}$ and $1.8 \mathrm{~mm})$ respectively with $P$ value 0.02 . The PRS thickness in patient and control group was $(3.8 \mathrm{~mm}$ and $4.1 \mathrm{~mm}$ ) respectively with $P$ value $<0.001$. While during rest, there was insignificant statistical difference in mean thickness of internal sphincter (in patients $2.1 \mathrm{~mm}$ and in control $2.4 \mathrm{~mm}$ with $P$ value 0.12 ) and transverse diameter of levator hiatus (in patients $3.7 \mathrm{~cm}$ and in control $3.5 \mathrm{~cm}$ with $P$ value 0.06). During squeezing, the mean PRS thickness (2.9 and 3.3), AP, transverse diameters $(5.8,3.9$, and $5.3,3.6)$, and hiatal area

Table 3 Grades of intussusception seen by 3D ultrasonography and defecography

\begin{tabular}{lll}
\hline Grades of intussusception & $\begin{array}{l}\text { 3D ultrasonography } \\
\text { No. of patients }\end{array}$ & $\begin{array}{l}\text { Defecography } \\
\text { No. of patients }\end{array}$ \\
\hline Grade I (rectal intussusception & 5 & 8 \\
Grade II (anorectal intussusception & 1 & 2 \\
\hline
\end{tabular}




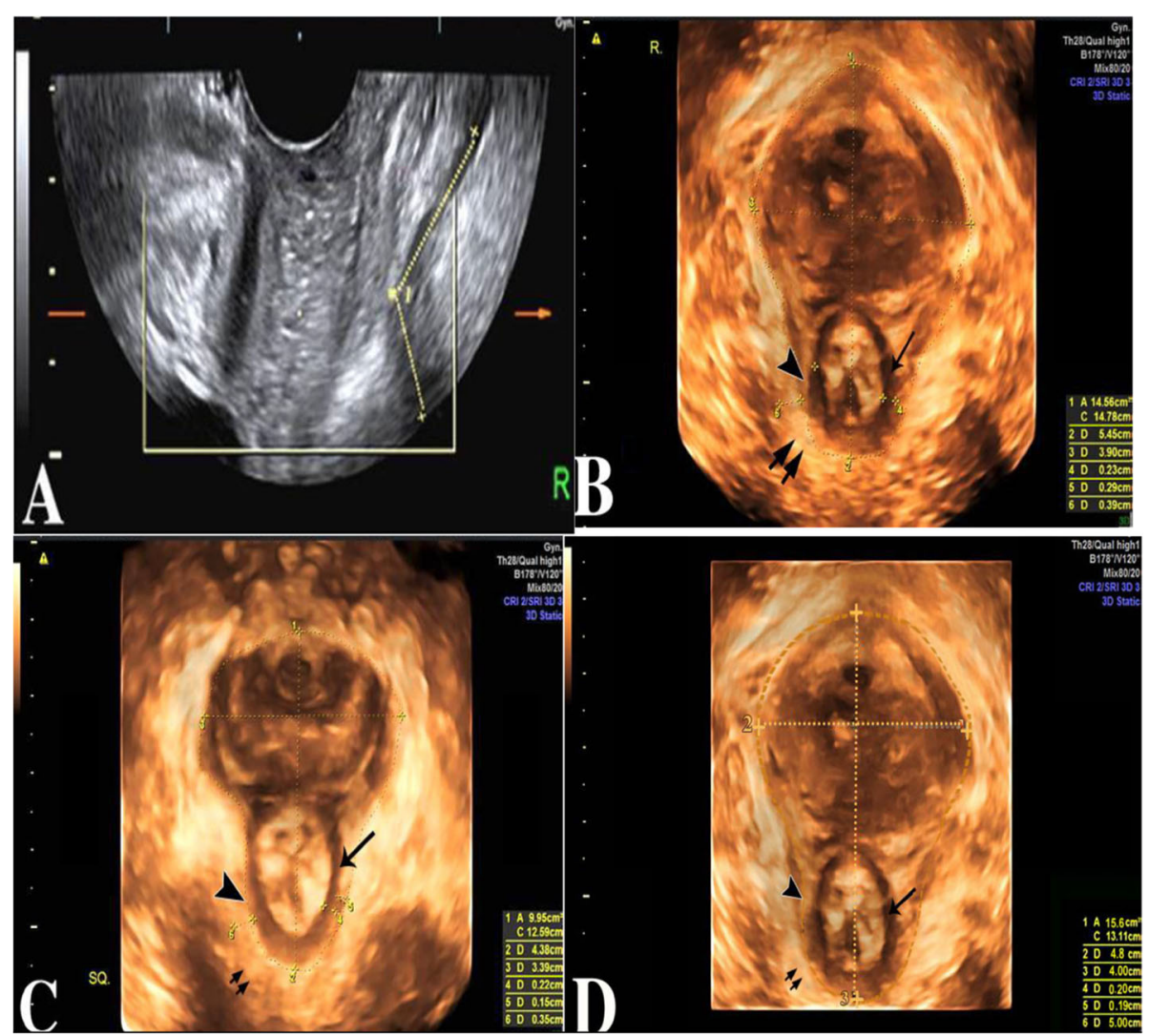

Fig. 1 Control group. Nulliparous female 20 years. 2D ultrasound shows a normal ARA $\left(100^{\circ}\right)$. No detected rectocele or intussusception. 3D ultrasound shows: At rest (b): levator area: transverse diameter $3.7 \mathrm{~cm}$. AP diameter $4.5 \mathrm{~cm}$. Hiatal area: $14.5 \mathrm{~cm}^{2}$. Thickness of internal sphincter $2 \mathrm{~mm}$ (Arrow). Thickness of external sphincter $1.9 \mathrm{~mm}$ (arrow head). Thickness of PRS about $4 \mathrm{~mm}$ (double arrows). During squeezing (c): levator area: transverse diameter $3.3 \mathrm{~cm}$. AP diameter $4.3 \mathrm{~cm}$. Hiatal area $9.9 \mathrm{~cm}^{2}$. Thickness of internal sphincter $1.9 \mathrm{~mm}$ (arrow). Thickness of external sphincter $1.5 \mathrm{~mm}$ (arrow head). Thickness of PRS about $3.6 \mathrm{~mm}$ (double arrows). During straining (d): levator area: transverse diameter $4 \mathrm{~cm}$. AP diameter $4.8 \mathrm{~cm}$. Hiatal area: $15.6 \mathrm{~cm}{ }^{2}$ thickness of internal sphincter $2 \mathrm{~mm}$ (arrow). Thickness of external sphincter $1.9 \mathrm{~mm}$ (arrow head). Thickness of PRS about $5 \mathrm{~mm}$ (double arrows)

(16.6 and 14.9) in patients and control group respectively were with statistically insignificant $P$ values.

Roc analysis confirmed these results, with area under curve (AUC) of 0.98 for hiatal area and cut-off value of $20.75 \mathrm{~cm}^{2}$ gives sensitivity of $100 \%$ and specificity of 95\% during straining (It indicates perfect test with high accuracy to discriminate between patients and controls).While AUC in resting is 0.0 and in squeezing is 0.01 indicative of poor accuracy during these phases.

Measurement of antero-posterior (AP) and transverse $(\mathrm{Tr})$ diameters of the levator hiatus during straining showed that using the cut off value $5.9 \mathrm{~cm}$ for (AP) diameter give sensitivity of $87 \%$ and specificity of $83 \%$, and cut off value $4.5 \mathrm{~cm}$ for (Tr) diameter give sensitivity of $80 \%$ and specificity of $77 \%$ for differentiation between patients and control group.

There was no significant difference between defecography and ultrasonography in measuring the anorectal angle in patients with obstructed defecation; the mean anorectal angle (ARA) by US was $(119.5 \pm 5.8)$ and by defecography, it was $(118 \pm 4.5)$.
During straining, anorectal angle also was measured by US in all patients and control group, to show the effect of rectal prolapse on anorectal angle; mean \pm SD of patients was $(119.5 \pm 5.8)$ while mean \pm SD of controls was $(96.3 \pm 4.9)$. Using independent $t$ test, there was a significant statistical difference $(P$ value $<$ 0.001) (Table 7). Roc analysis confirmed these results, with area under curve (AUC) of .992 for anorectal angle (ARA).Cut-off value of $105^{\circ}$ gives sensitivity of $98 \%$ and specificity of $90 \%$.

\section{Discussion}

Chronic constipation is a common clinical problem, affecting adult population and more common in women. The obstructed defecation syndrome results from either a dysfunction of the muscles that take part in the defecation process or an anatomical abnormality of the organs contained in the pelvis area [2].

The current study was interested in evaluation of pelvic floor dysfunction by ultrasound and comparing the results with defecography in adult females 


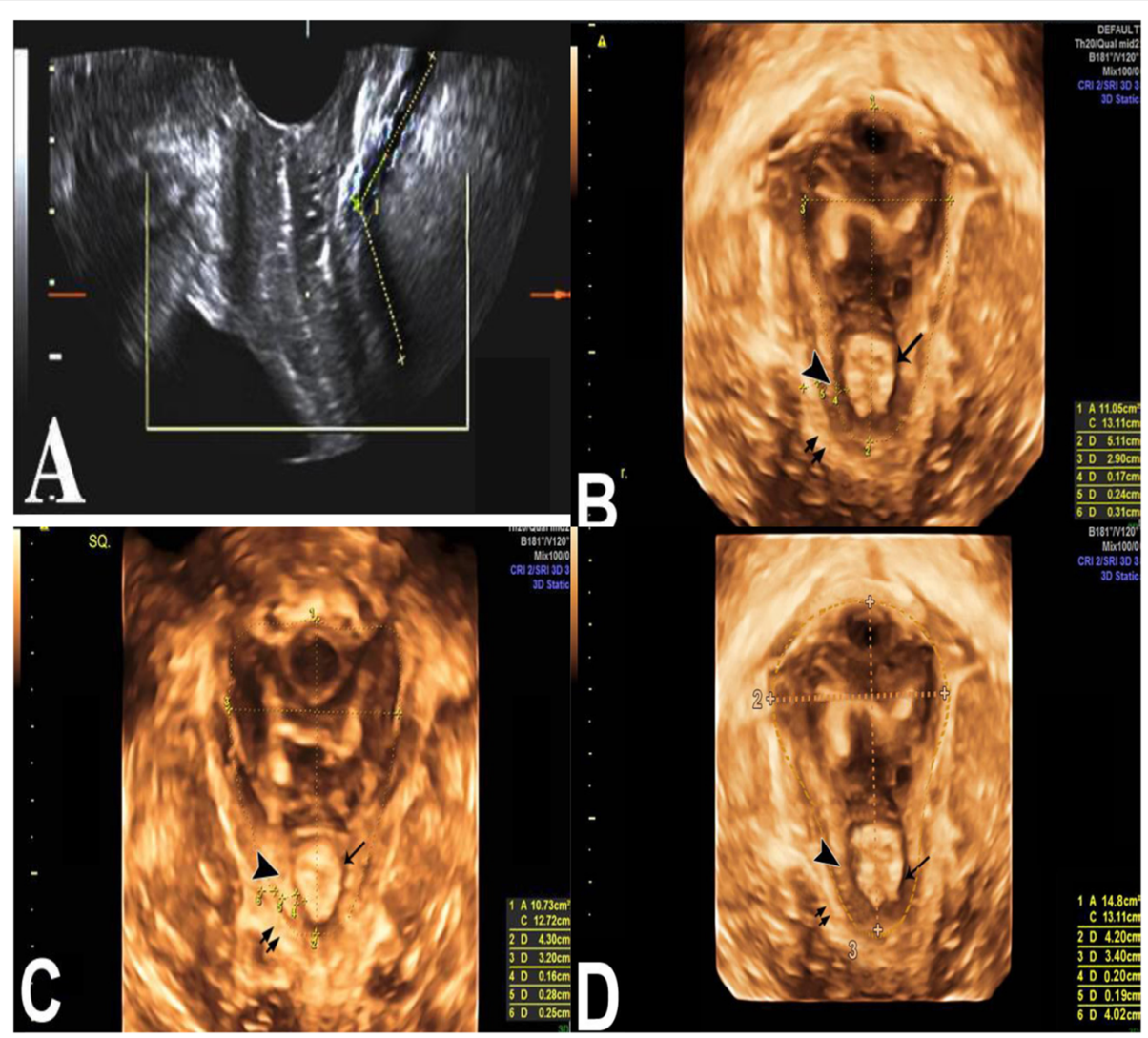

Fig. 2 Control group. Nulliparous female patient 23 years old. 2D ultrasound shows: (a): normal rectum, vagina, and anal canal. Anorectal angle $\left(100^{\circ}\right)$. No detected rectocele or intussusception. 3D ultrasound shows: At rest (b): levator area: transverse diameter $3 \mathrm{~cm}$. AP diameter $5 \mathrm{~cm}$. Hiatal area: $11.5 \mathrm{~cm}^{2}$. Thickness of internal sphincter $1.7 \mathrm{~mm}$ (arrow). Thickness of external sphincter $2.4 \mathrm{~mm}$ (arrow head). Thickness of PRS about $3.7 \mathrm{~mm}$ (double arrows). During squeezing (c): levator area: transverse diameter $3.3 \mathrm{~cm}$. AP diameter $4.3 \mathrm{~cm}$. Hiatal area: $10.7 \mathrm{~cm}^{2}$. Thickness of internal sphincter $1.7 \mathrm{~mm}$ (arrow). Thickness of external sphincter $2.8 \mathrm{~mm}$ (arrow head). Thickness of PRS about $2.6 \mathrm{~mm}$ (double arrows). During straining (d): levator area: transverse diameter $3.4 \mathrm{~cm}$. AP diameter $4.2 \mathrm{~cm}$. Hiatal area:

$14.8 \mathrm{~cm}^{2}$. Thickness of internal sphincter $2 \mathrm{~mm}$ (Arrow). Thickness of external sphincter $1.9 \mathrm{~mm}$ (arrow head). The thickness of PRS about $4 \mathrm{~mm}$ (double arrows)

with obstructed defecation syndrome. The results showed that the sensitivity of rectocele detection by defecography was (100\%) and by ultrasonography was $(85 \%)$. This is in agreement with Beer-Gabel and Carter [8] who found a high prevalence of rectocele on defecography (96\%) compared to ultrasound (83\%). Three rectoceles were missed by US due to small size $(<2 \mathrm{~cm})$ and complete emptying on evacuation proctography.

Measurements of rectocele depth showed limited agreement between the two methods in this study as the rectocele appeared smaller in depth on ultrasonography compared with defecography; the mean depth of rectocele was $2.7 \pm 0.6 \mathrm{~cm}$ and $3.8 \pm 0.4 \mathrm{~cm}$ by US and defecography respectively. This can cope with Beer-Gabel et al. [9] who reported that the mean depth of rectoceles as diagnosed by defecography was $3.0 \pm 0.36 \mathrm{~cm}$ and by US was $2.69 \pm$ $0.19 \mathrm{~cm}$.
Concerning intussusception, there was a difference between the two techniques in detection rate; the sensitivity of defecography in detection of intussusception was (90\%) and by US, it was (50\%). This copes with Beer-Gabel and Carter [8] who reported that $(94 \%)$ of cases of intussusception were diagnosed by defecography while only ( $75 \%$ ) by US. This can be explained by the variation in the ability of the patient to fully strain during introital US, and perhaps due to patient reticence because of the perineal proximity to the probe, also sitting position during defecation proctography mimicking actual defecation process, enhanced the appearance of intussusception.

The greatest utility of ultrasonographic imaging in patients with obstructed defecation is the identification of anatomical and functional abnormalities of the pelvic floor muscles. It can identify not just the clinical manifestation (rectocele or intussusception) but the underlying abnormality itself. Global levator ani damage, 


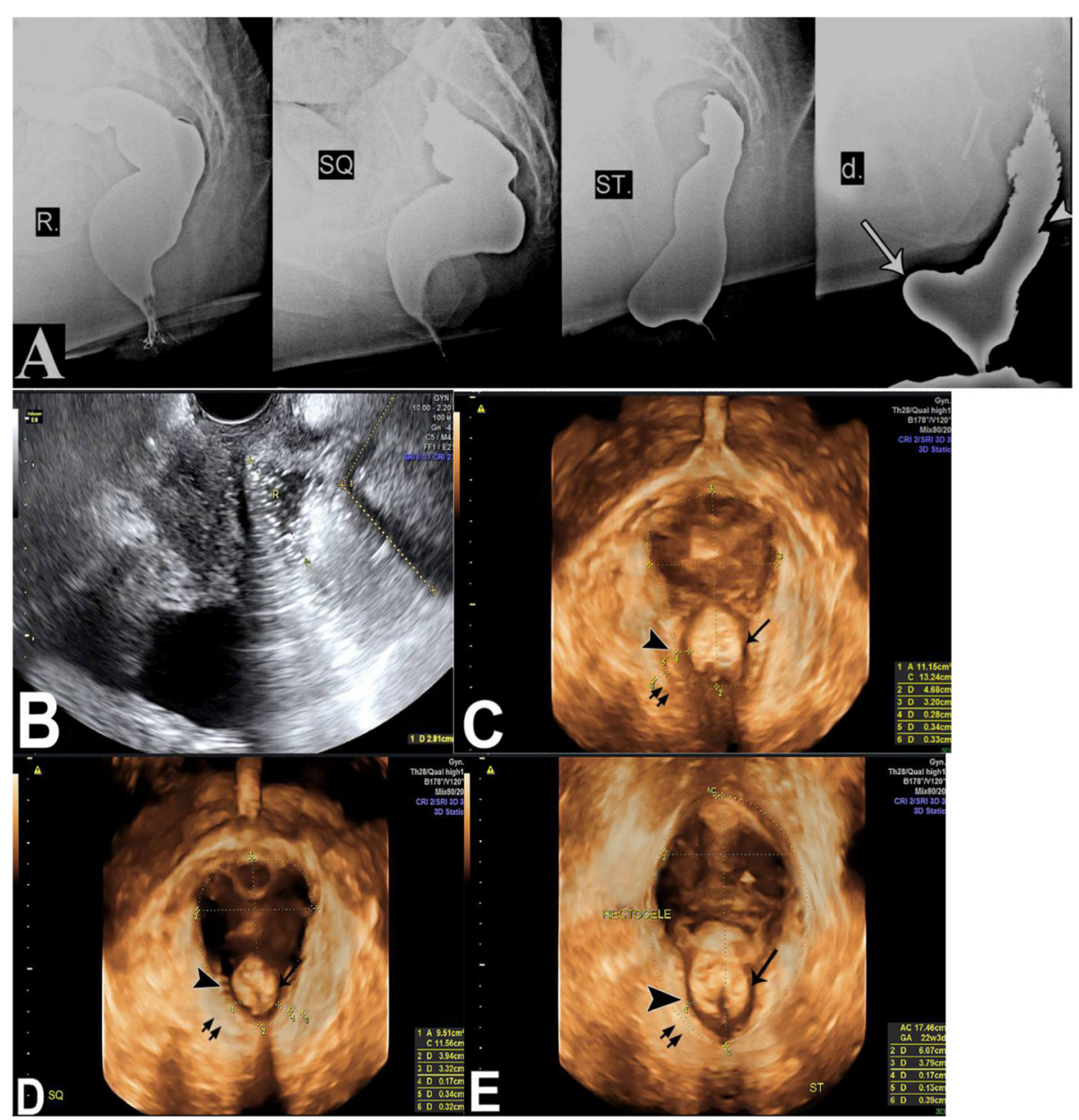

Fig. 3 Female patient aged 34 years with history of repeated four normal deliveries and complaining of chronic constipation. Defecography shows: (a): anterior rectocele about $4 \mathrm{~cm}$ (arrow). Evidence of rectal intussusception (arrow head). Lax pelvic floor. Anorectal angle $\left(95^{\circ}\right) .2 \mathrm{D}$ ultrasound shows: (b): anterior rectocele filled with gel measures about $2.5 \mathrm{~cm}$ and measures about $1.8 \mathrm{~cm}$ empty. Anorectal angle $\left(102^{\circ}\right)$. 3D ultrasound shows: at rest (c): levator area: transverse diameter $3.2 \mathrm{~cm}$. AP diameter $4.6 \mathrm{~cm}$. Hiatal area: $11.4 \mathrm{~cm}^{2}$. Thickness of internal sphincter $2.7 \mathrm{~mm}$ (Arrow). Thickness of external sphincter $3.4 \mathrm{~mm}$ (arrow head). Thickness of PRS about $3 \mathrm{~mm}$ (double arrows). During squeezing (d): levator area: transverse diameter $3.3 \mathrm{~cm}$. AP diameter $3.9 \mathrm{~cm}$. Hiatal area: $10.7 \mathrm{~cm} 2$. Thickness of internal sphincter $1.7 \mathrm{~mm}$ (arrow). Thickness of external sphincter $3 \mathrm{~mm}$ (arrow head). Thickness of PRS about $3.2 \mathrm{~mm}$ (double arrows). During straining (e): anterior rectocele measures about $2.8 \mathrm{~cm}$. Wide levator area: transverse diameter $4 \mathrm{~cm}$. AP diameter $6 \mathrm{~cm}$. Hiatal area: $20.3 \mathrm{~cm}^{2}$. Attenuation of internal sphincter $1.7 \mathrm{~mm}$ (arrow). Attenuation of external sphincter $1.5 \mathrm{~mm}$ (arrow head). Attenuation of PRS about $2.9 \mathrm{~mm}$ (double arrows)

avulsion defects, abnormal levator ani contractility, and a pathologically enlarged levator hiatus (ballooning) were also diagnosed by introital US, while defecography cannot identify this. This study included three patients (15\%) with levator muscle avulsion that could not be diagnosed by defecography.

In the current study, the morphology and dimensions of the levator hiatus were compared between patients with obstructed defecation and control group. The mean size of the levator area in patients during straining was $\left(23.1 \pm 1.0 \mathrm{~cm}^{2}\right)$ larger compared with the mean size in control group $\left(15.2 \pm 0.6 \mathrm{~cm}^{2}\right)$; the morphology in the diseased patients tended to be more circular due to ballooning of hiatal area.
Braekken et al. [10] reported similar findings; their results shown that mean size of levator area in patients and control group were $23.2 \pm 5.3 \mathrm{~cm}^{2}$ and $16.6 \pm$ $2.82 \mathrm{~cm}^{2}$ respectively.

Dietz [11] said that the most accurate phase in detection of rectal prolapse and so measuring the hiatal area distensibility was during straining with cut off value $25 \mathrm{~cm}^{2}$, yielding a sensitivity of $70 \%$ and specificity of $83 \%$. In our study, we noticed that the parameters describing the size and distensibility of the hiatus area should be investigated during maximum Valsalva (straining), which is the most accurate phase in detection of its distensibility with cut off value $20.7 \mathrm{~cm}^{2}$, give a sensitivity of $100 \%$ and specificity of 


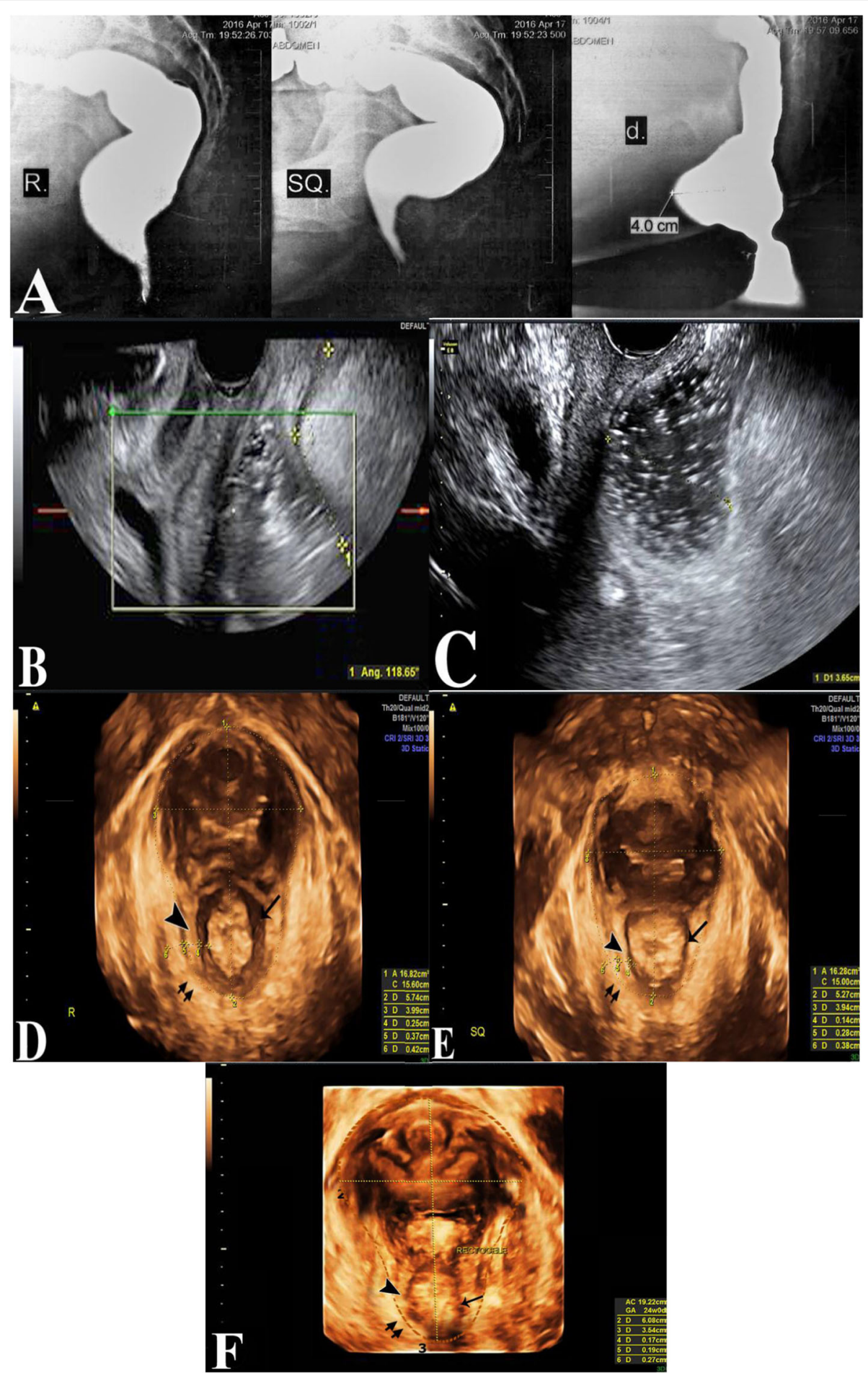

Fig. 4 Female patient aged 45 years with history of three vaginal deliveries and complaining of feeling a vaginal lump and chronic constipation. Defecography shows: a anterior rectocele about $4 \mathrm{~cm}$. Anorectal angle $\left(120^{\circ}\right)$. $2 \mathrm{D}$ ultrasound: $\mathbf{b}$ resting: anorectal angle $\left(118^{\circ}\right)$. c Straining: anterior rectocele about $1.4 \mathrm{~cm}$ empty and $2.6 \mathrm{~cm}$ filled with gel material and invaginating the rectovaginal septum. Anorectal angle $\left(118^{\circ}\right)$. $3 \mathrm{D}$ ultrasound shows: at rest (d): levator area: transverse diameter $3.9 \mathrm{~cm}$. AP diameter $5.7 \mathrm{~cm}$. Hiatal area: $16.8 \mathrm{~cm}^{2}$. Thickness of internal sphincter $2.6 \mathrm{~mm}$ (arrow). Thickness of external sphincter $3.7 \mathrm{~mm}$ (arrow head). Thickness of PRS about $4 \mathrm{~mm}$ (double arrows). During squeezing (e): levator area: transverse diameter $3.9 \mathrm{~cm}$. AP diameter $5.3 \mathrm{~cm}$. Hiatal area: $16.3 \mathrm{~cm}{ }^{2}$. Decreased thickness of internal sphincter $1.4 \mathrm{~mm}$ (arrow). Thickness of external sphincter $2.8 \mathrm{~mm}$ (arrow head). Thickness of PRS about $3.7 \mathrm{~mm}$ (double arrows). During straining (f): anterior rectocele invaginating the rectovaginal septum. Wide levator area: transverse diameter $4.3 \mathrm{~cm}$. AP diameter $6.2 \mathrm{~cm}$. Hiatal area: $20.7 \mathrm{~cm}$. Attenuation of internal sphincter $1.6 \mathrm{~mm}$ (arrow). Attenuation of external sphincter $1.7 \mathrm{~mm}$ (arrow head). Attenuation of PRS about $2.7 \mathrm{~mm}$ (double arrows) 

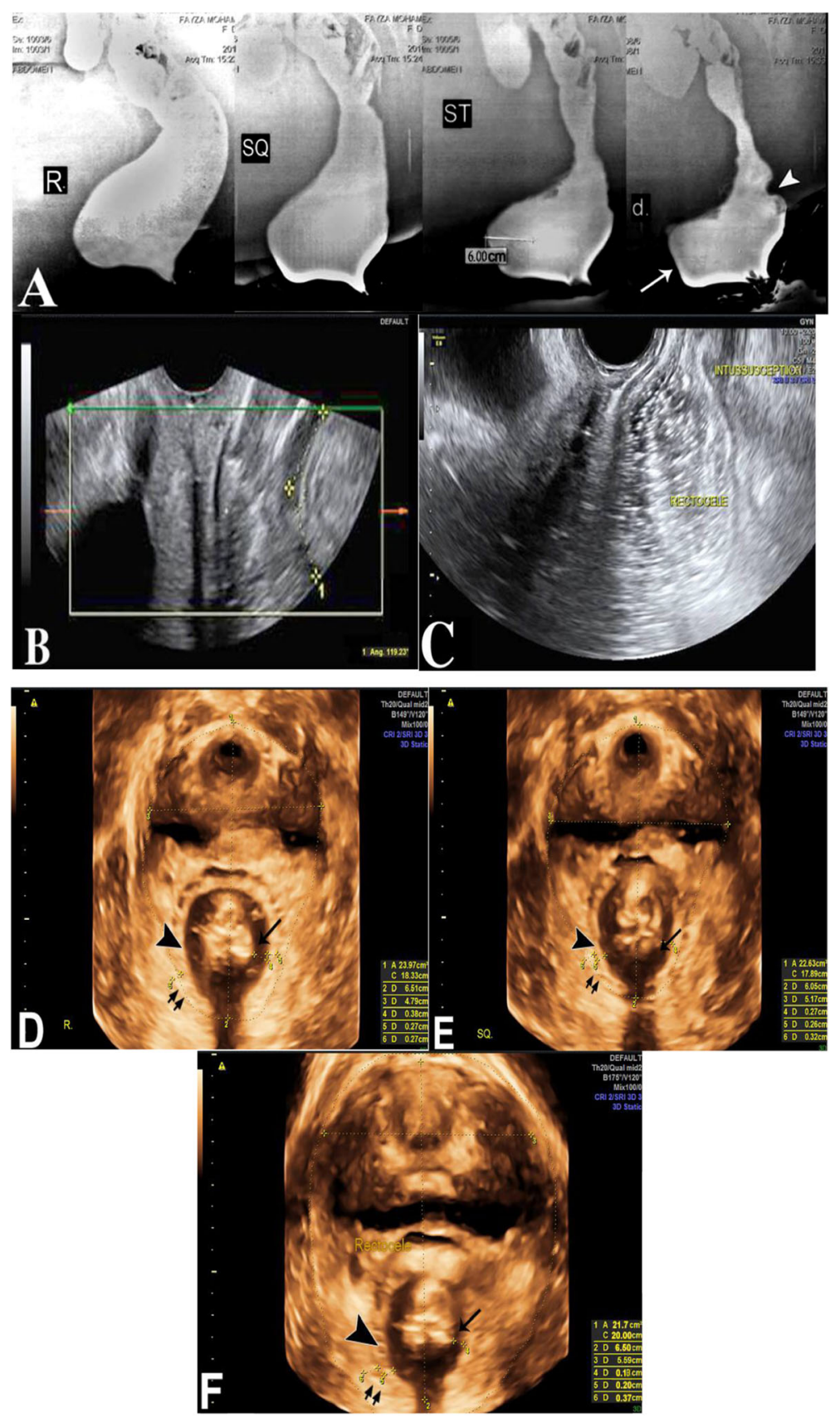

Fig. 5 Obese female patient aged 50 years old with history of five vaginal deliveries and complaining of incomplete evacuation. Defecography shows: (a): anterior rectocele measures $6 \mathrm{~cm}$ (arrow). Evidence of rectal intussusception (arrow). Lax pelvic floor. Anorectal angle $\left(115^{\circ}\right) .2 \mathrm{D}$ ultrasound shows: b Resting: anorectal angle $\left(119^{\circ}\right)$. c Straining: large rectocele filled with gel and appears on straining measures $4 \mathrm{~cm}$ and $2 \mathrm{~cm}$ empty. Evidence of rectal intussusception. Anorectal angle $\left(119^{\circ}\right)$. 3D ultrasound shows: at rest: (d): levator area: transverse diameter $4.7 \mathrm{~cm}$. AP diameter $6.5 \mathrm{~cm}$. Hiatal area: $18.3 \mathrm{~cm}^{2}$. Thickness of internal sphincter $3 \mathrm{~mm}$ (arrow).Thickness of external sphincter $2.7 \mathrm{~mm}$ (arrow head). Thickness of PRS about $3.7 \mathrm{~mm}$ (double arrows). During squeezing: (e): levator area: transverse diameter $5 \mathrm{~cm}$. AP diameter $6.6 \mathrm{~cm}$. Hiatal area: $17 \mathrm{~cm} 2$. Thickness of internal sphincter $2.7 \mathrm{~mm}$ (arrow). Thickness of external sphincter $2.4 \mathrm{~mm}$ (arrow head). Thickness of PRS about $3 \mathrm{~mm}$ (double arrows). During straining: $(\mathbf{f})$ : anterior rectocele invaginating the rectovaginal septum. Wide levator area: transverse diameter $5 \mathrm{~cm}$. AP diameter $6.5 \mathrm{~cm}$. Hiatal area: $21.7 \mathrm{~cm}^{2}$. Thickness of internal sphincter $2.3 \mathrm{~mm}$ (arrow) attenuated at Lt side to $1.3 \mathrm{~mm}$. Thinning of external sphincter $1.8 \mathrm{~mm}$ (arrow head). Thickness of PRS about $3.7 \mathrm{~mm}$ (double arrows) 
Table 4 Measured parameters in the patients and the control group (mean \pm SD) during resting

\begin{tabular}{llll}
\hline $\begin{array}{l}\text { 3D Ultrasonography } \\
\text { measurements }\end{array}$ & $\begin{array}{l}\text { Patients } \\
\text { Mean } \pm \text { SD }\end{array}$ & $\begin{array}{l}\text { Control group } \\
\text { Mean } \pm \text { SD }\end{array}$ & $P$ value \\
\hline $\begin{array}{llll}\text { Levator Hiatus } \\
\text { AP Diameter }(\mathrm{cm})\end{array}$ & $5.7 \pm 0.7$ & $4.4 \pm 0.4$ & $<0.001$ \\
Tr Diameter (cm) & $3.7 \pm 0.4$ & $3.5 \pm 0.3$ & 0.06 \\
Area (cm2) & $16.3 \pm 1.9$ & $10.4 \pm 0$. & $<0.001$ \\
IS Thickness (mm) & $2.1 \pm 0.5$ & $2.4 \pm 0.7$ & 0.12 \\
ES Thickness (mm) & $1.8 \pm 0.2$ & $2.5 \pm 0.5$ & $<0.001$ \\
PRS Thickness (mm) & $2.7 \pm 0.2$ & $3.1 \pm 0.3$ & $<0.001$ \\
\hline
\end{tabular}

95\%; on the other hand, squeezing phase shown insignificant difference between cases and control with $(P$ value $>0.05)$.

Measurement of AP and transverse diameters of hiatal area also give overall view of the hiatal distensibility in patients with obstructed defecation. This study showed a significant statistical difference between patients and control group during maximum Valsalva $(P$ value $<0.001)$. Resting and squeezing phases showed insignificant statistical difference with ( $P$ value $>0.05)$, so straining could be considered the most sensitive phase in measuring AP and transverse diameters of the hiatal area. These results are in agreement with Braekken et al. [10] who reported that straining is the most accurate phase in measuring the dimensions of hiatal area.

In this study, there was attenuation in the thickness of anal sphincters and puborectalis muscle (part of levator ani muscle) during Valsalva in patients with rectal prolapse and obstructed defecation compared with the control group; the mean thickness of IS, ES, and PRS in patient group were $1.8 \pm 0.6 \mathrm{~mm}, 1.6 \pm 0.3 \mathrm{~mm}$, and $3.8 \pm$ $0.5 \mathrm{~mm}$ respectively, while the mean thickness of these parameters in control group were $2.8 \pm 0.5 \mathrm{~mm}, 1.8 \pm$ $0.18 \mathrm{~mm}$, and $4.1 \pm 0.5 \mathrm{~mm}$ respectively with $(P$ value $<$ 0.001). These results are not matched with Hall et al.

Table 5 Measured parameters in the patients and the control group (mean $\pm \mathrm{SD}$ ) during squeezing

\begin{tabular}{llll}
\hline $\begin{array}{l}\text { 3D Ultrasonography } \\
\text { measurements }\end{array}$ & $\begin{array}{l}\text { Patients } \\
\text { Mean } \pm \text { SD }\end{array}$ & $\begin{array}{l}\text { Control group } \\
\text { Mean } \pm \text { SD }\end{array}$ & $P$ value \\
\hline Levator Hiatus & & & \\
AP Diameter $(\mathrm{cm})$ & $5.8 \pm 0.9$ & $5.3 \pm 0.4$ & 0.2 \\
Tr Diameter $(\mathrm{cm})$ & $3.9 \pm 0.4$ & $3.6 \pm 0.4$ & 0.16 \\
Area (cm2) & $16.6 \pm 1.1$ & $14.9 \pm 0.5$ & 0.3 \\
IS Thickness (mm) & $1.9 \pm 0.2$ & $2.6 \pm 0.5$ & $<0.001$ \\
ES Thickness (mm) & $2.8 \pm 0.2$ & $2.3 \pm 0.5$ & $<0.001$ \\
PRS Thickness (mm) & $2.9 \pm 0.63$ & $3.3 \pm 0.4$ & 0.3 \\
\hline
\end{tabular}

Table 6 Measured parameters in the patients and the control group (mean $\pm \mathrm{SD}$ ) during straining

\begin{tabular}{llll}
\hline $\begin{array}{l}\text { 3D Ultrasonography } \\
\text { measurements }\end{array}$ & $\begin{array}{l}\text { Patients } \\
\text { Mean } \pm \text { SD }\end{array}$ & $\begin{array}{l}\text { Control group } \\
\text { Mean } \pm \text { SD }\end{array}$ & $P$ value \\
\hline $\begin{array}{l}\text { Levator Hiatus } \\
\text { AP Diameter (cm) }\end{array}$ & $6.6 \pm 0.4$ & $4.6 \pm 0.3$ & $<0.001$ \\
Tr Diameter (cm) & $4.9 \pm 0.4$ & $3.9 \pm 0.3$ & $<0.001$ \\
$\quad$ Area (cm2) & $23.1 \pm 1.0$ & $15.2 \pm 0.6$ & $<0.001$ \\
IS Thickness (mm) & $1.8 \pm 0.6$ & $2.8 \pm 0.5$ & $<0.001$ \\
ES Thickness (mm) & $1.6 \pm 0.3$ & $1.8 \pm 0.18$ & 0.02 \\
PRS Thickness (mm) & $3.8 \pm 0.5$ & $4.1 \pm 0.5$ & $<0.001$
\end{tabular}

Receiver operator curve for the diagnosis of abnormal hiatal distensibility ("ballooning") on the basis of symptoms of prolapse during maximum Valsalva (straining)

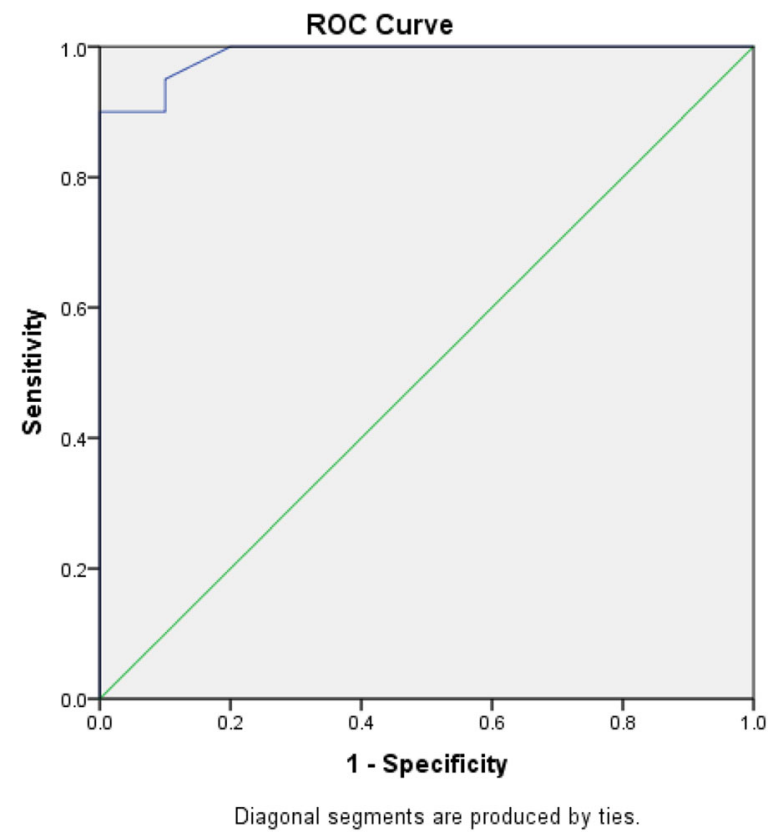

[12], who found no significant difference for thickness of these muscles $(P$ value of all $>0.05)$. This difference could be attributed to the successive vaginal deliveries in patients of our study and the possible complications of deliveries in our patients.

The measurement of anorectal angle during straining showed a significant statistical difference between patients and control group as the mean ARA of the patients was $(119.5 \pm 5.8)$ and of control group it was $(96.3 \pm 4.9)$. These results run in accordance with Beer-Gabel et al. [9] who reported that the mean ARA of patients and control group were $(123.3 \pm 4.32)$ and $(116.4 \pm 3.32)$ respectively with good agreement between ultrasonography and defecography in measuring the ARA. 
Table 7 Measurement of anorectal angle in the patients and the control group (mean \pm SD) during straining

\begin{tabular}{llcc}
\hline $\begin{array}{l}\text { 3D Ultrasonography } \\
\text { measurements }\end{array}$ & $\begin{array}{l}\text { Patients } \\
\text { Mean } \pm \text { SD }\end{array}$ & $\begin{array}{l}\text { Control group } \\
\text { Mean } \pm \text { SD }\end{array}$ & $P$ value \\
\hline Anorectal angle & $119.5 \pm 5.8$ & $96.3 \pm 4.9$ & $<0.001$ \\
\hline $\begin{array}{l}\text { Receiver operator curves for the diagnosis of anorectal angle sensitivity and } \\
\text { specificity in patients with obstructed defecation during straining }\end{array}$
\end{tabular}

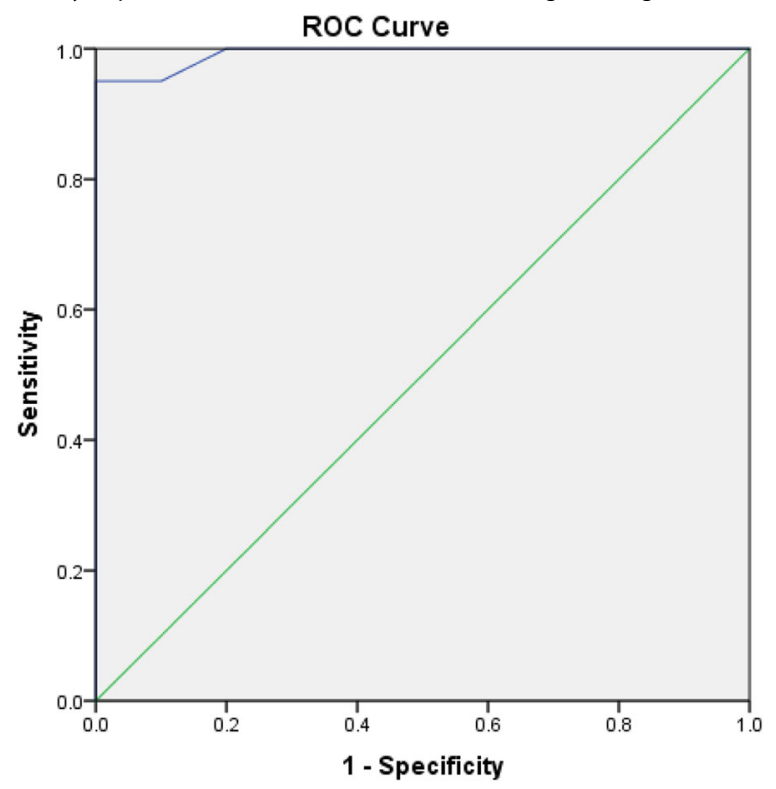

Diagonal segments are produced by ties.
A previous study done by Grasso et al. [13] reported that ultrasound may be valuable as an initial test or screening method in patients with defecatory disorders, avoiding more invasive tests when findings are positive. While, negative findings on ultrasound may need confirmation by defecation proctography. From this study and our results, it is better to augment results of both techniques that are complementary to each other's.

\section{Limitation}

There is a limited number of patients in this study.

\section{Recommendations}

Further study with a large number of patients is recommended.

\section{Conclusion}

Ultrasound is considered an available, cheap, and noninvasive technique complementary to defecography in the diagnostic work-up of patients with symptoms of obstructed defecation. Defecography is more sensitive than US in detecting rectocele and rectal intussusception; on the other hand, ultrasound can diagnose the levator muscle attenuation and avulsion, thickness of IS, ES, PRS, and distensibility of the hiatal area, while defecography cannot. So ultrasound can be considered a complementary test to defecation proctography in investigation of patients with obstructed defecation syndrome.

\section{Abbreviations \\ 2D: Two-dimension; 3D: Three-dimensional; 3DUS: Three-dimensional ultrasound; AP: Antero-posterior; ARA: Anorectal angle; AUC: Area under curve; Cm: Centimeter; ES: External sphincter; IS: Internal sphincter; MHz: Megahertz; mL: Milliliter; mm: Millimeter; $P$ value: Probability value; PRS: Puborectalis sling; ROC curve: Receiver operating characteristic curve; SD: Standard deviation; Tr: Transverse; US: Ultrasound}

\section{Acknowledgments}

To technicians at radiology center who help in examination of patients.

\section{Authors' contributions}

MAL: writing of the manuscript of the research, final revision of data, and radiological images. Finalization of the research manuscript. MS: idea of the research, radiological examinations of patients, and revision of data. NME: collecting of data and radiological examination of patients (under supervision). WMT: surgical procedure for patients and revision of data. All authors read and approved the final manuscript.

\section{Funding}

Not applicable (no funding).

\section{Availability of data and materials}

Authors can confirm that all relevant data are included in the article and/or its supplementary information files.

\section{Ethics approval and consent to participate}

This study was approved by the Medical Research Ethics Committee of Mansoura University and written informed consent to participate was obtained from all patients. Ethics committee reference number (Code No. MS/796).

\section{Consent for publication}

All patients included in this research gave written informed consent to publish the data contained within this study.

\section{Competing interests}

The authors declare that they have no competing interests.

\section{Author details}

${ }^{1}$ Radio Diagnosis, Mansoura University Hospital, Mansoura, Egypt. ${ }^{2}$ Ano-rectal Surgery, Mansoura University Hospital, Mansoura, Egypt.

Received: 10 December 2019 Accepted: 17 December 2019 Published online: 31 December 2019

\section{References}

1. Valsky DV, Yagel S (2007) Three-dimensional transperineal ultrasonography of the pelvic floor. J Ultrasound Med 26:1373-1387

2. Burrows LJ, Meyn LA, Walters MD et al (2004) Pelvic symptoms in women with pelvic organ prolapse. Obstet Gynecol 104:982-988

3. Dietz HP, Shek C, Clarke B (2005) Biometry of the pubovisceral muscle and levator hiatus by three-dimensional pelvic floor ultrasound. Ultrasound Obstet Gynecol 25:580-585

4. Ng CC, Lee LC, Han WH (2005) Use of three-dimensional ultrasound scan to assess the clinical importance of midurethral placement of the tension-free vaginal tape (TVT) for treatment of incontinence. Int Urogynecol J Pelvic Floor Dysfunct 16:220-225

5. Dietz HP (2006) Pelvic floor ultrasound. Curr Med Imaging Rev 2(2):271-290

6. Dalpiaz O, Curti P (2006) Role of perineal ultrasound in the evaluation of urinary stress incontinence and pelvic organ prolapse: a systematic review. Neurourol Urodyn 25:301-306 
7. Dietz HP, Steensma AB (2005) Posterior compartment prolapse on two dimensional and three dimensional pelvic floor ultrasound: the distinction between true rectocele, perineal hypermobility and enterocele. Ultrasound Obstet Gynecol 26(1):73-77

8. Beer-Gabel M, Carter D (2015) Comparison of dynamic transperineal ultrasound and defecography for the evaluation of pelvic floor disorders. Int J Color Dis 30:835-841

9. Beer-Gabel M, Teshler M, Schechtman E et al (2004) Dynamic transperineal ultrasound vs. defecography in patients with evacuatory difficulty: a pilot study. Int J Color Dis 19:60-67

10. Braekken IH, Majida M, Ellstrom EM et al (2013) Are pelvic floor muscle thickness and size of levator hiatus associated with pelvic floor muscle strength, endurance and vaginal resting pressure in women with pelvic organ prolapse? Neurourol Urodyn 33:115-120

11. Dietz HP (2010) Pelvic floor ultrasound: a review. AJOG 202:321-334

12. Hall RJ, Rogers RG, Saiz L et al (2007) Translabial ultrasound assessment of the anal sphincter complex: normal measurements of the internal and external anal sphincters at the proximal, mid, and distal levels. Int Urogynecol J 18:881-888

13. Grasso RF, Piciucchi S, Quattrocchi CC et al (2007) Posterior pelvic floor disorders: a prospective comparison using introital ultrasound and colpocystodefecography. Ultrasound Obstet Gynecol 30:86-94

\section{Publisher's Note}

Springer Nature remains neutral with regard to jurisdictional claims in published maps and institutional affiliations.

\section{Submit your manuscript to a SpringerOpen ${ }^{\circ}$ journal and benefit from:}

- Convenient online submission

- Rigorous peer review

- Open access: articles freely available online

- High visibility within the field

- Retaining the copyright to your article 